\title{
The bipolar spectrum: origins, validation and critique Hagop Akiskal
}

Address: Department of Psychiatry, University of California at San Diego, USA

from International Society on Brain and Behaviour: 3rd International Congress on Brain and Behaviour

Thessaloniki, Greece. 28 November - 2 December 2007

Published: 17 April 2008

Annals of General Psychiatry 2008, 7(Suppl I):S78 doi:I0.II86/1744-859X-7-SI-S78

This abstract is available from: http://www.annals-general-psychiatry.com/content/7/SI/S78

(c) 2008 Akiskal; licensee BioMed Central Ltd.

The roots of the bipolar spectrum go back to ancient Greek medicine linking temperaments to melancholia, fear to melancholia, and melancholia to mania. The subject was taken up by French alienists in the mid nineteenth century and then given international status by German psychiatrists. DSM-II had a broad concept of manic-depressive illness. DSM-III (and ICD-10) introduced the broad concept of (major) depression, which undermined the continuum concept between depressive, anxiety, and bipolar disorders. Now that comorbidity is fashionable in both clinical and epidemiological studies, and subthreshold psychiatry is being taken seriously, a great deal has been published internationally to convincingly argue for the necessity of returning to the concept of a dimensional extension from bipolar temperaments through recurrent depression, "soft bipolar spectrum", all the way to the "hard spectrum" and psychotic edge of the spectrum. Despite opinions to the contrary, extensive epidemiologic, course, clinical, and familial-genetic evidence supports the concept of a broad spectrum of affective illness. There may even be some intersection of the affective and schizophrenic spectra. This perspective is also compatible with distinct categorical subtypes within the broad spectrum, because prognostic and therapeutic implications are relevant for clinical practice involving distinct subtypes. The main critiques come from those who live in the "unipolar" world, and the fields of addictive and "borderline" psychiatry with accusations of "nosological imperialism" on the part of those who subscribe to the broad bipolar view. Finally, treatments have been developed largely for the classical, well-defined hard spectrum conditions. Preventive psychiatry, including that of suicide, is an important driving force to address these therapeutic challenges. 